\title{
Method for Friction Force Estimation on the Flank of Cutting Tools
}

\author{
Luis Huerta, ${ }^{1}$ Alejandro Lozano-Guzmán, ${ }^{1}$ Horacio Orozco-Mendoza, ${ }^{2}$ \\ and Juan Carlos Jauregui-Correa ${ }^{3}$ \\ ${ }^{1}$ CICATA-IPN Unidad Querétaro, Cerro Blanco No. 141, Col. Colinas del Cimatario, Queretaro, QRO, Mexico \\ ${ }^{2}$ Instituto Tecnológico de Celaya, Antonio García Cubas 600 Esq. Avenida Tecnológico, 38010 Celaya, GTO, Mexico \\ ${ }^{3}$ Division de Investigacion y Posgrado, Facultad de Ingeniería, Universidad Autonoma de Queretaro, \\ 76010 Santiago de Queretaro, QRO, Mexico
}

Correspondence should be addressed to Juan Carlos Jauregui-Correa; jc.jauregui@uaq.mx

Received 17 March 2017; Revised 6 May 2017; Accepted 8 May 2017; Published 3 July 2017

Academic Editor: Marc Thomas

Copyright (C) 2017 Luis Huerta et al. This is an open access article distributed under the Creative Commons Attribution License, which permits unrestricted use, distribution, and reproduction in any medium, provided the original work is properly cited.

\begin{abstract}
Friction forces are present in any machining process. These forces could play an important role in the dynamics of the system. In the cutting process, friction is mainly present in the rake face and the flank of the tool. Although the one that acts on the rake face has a major influence, the other one can become also important and could take part in the stability of the system. In this work, experimental identification of the friction on the flank is presented. The experimental determination was carried out by machining aluminum samples in a CNC lathe. As a result, two friction functions were obtained as a function of the cutting speed and the relative motion of the contact elements. Experiments using a worn and a new insert were carried out. Force and acceleration were recorded simultaneously and, from these results, different friction levels were observed depending on the cutting parameters, such as cutting speed, feed rate, and tool condition. Finally, a friction model for the flank friction is presented.
\end{abstract}

\section{Introduction}

Due to forces and temperature variations, the cutting process is highly nonlinear. Also, this process is affected by other factors such as speed and depth of cut, feed rate, cutting tool geometric, and material properties [1]. Many of these effects occur because of the relative motion between the working piece and the tool, and therefore friction forces are present.

Friction on the machining process has been studied for decades and significant theories have been proposed for describing the cutting process [2]. The one studying the sliding and secondary zones of the material work are presented at [3]. All these researches lead to intensive use of finite element models, such as the one presented by [4].

The general objective of the application of finite elements is the characterization of the elements in contact and the flow of stresses $[5,6]$. Other research area is friction measurements as reported by [7]. In this matter, the relation of the friction with the cutting parameters, such as the cutting speed, was reported in [8]. The influences of cutting forces, contact length, shear angle, and temperatures are studied by [9-11], and friction related effects associated with geometric and internal material properties are reported by [12-14].

From these works, it can be established that friction is an instability factor, so it could generate chatter vibration. This is proposed by Wiercigroch and Krivtsov [15], and despite the fact that in a machining process the major friction effect occurs at the rake of the tool, it also exists on the flank of the tool.

In the literature, the flank of the tool has been just related to chatter by means of the process damping effect at low speed [16-18]. However, the friction effect on the flank is generally neglected.

Taking into account the fact that the cutting process is highly nonlinear, the assumption that friction on the flank can be neglected is untrue, because in any dynamic nonlinear system, a small perturbation tends to produce high influence on the response. This is important in chatter, where the 


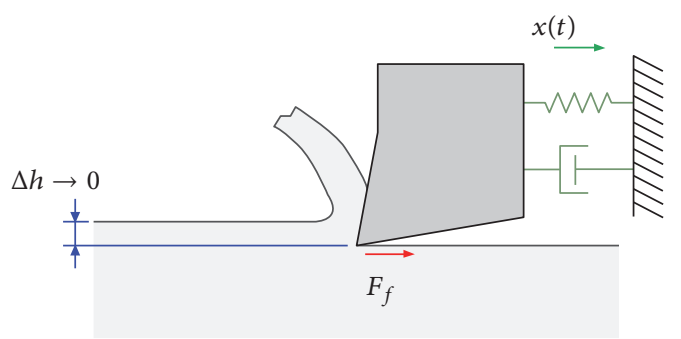

FIGURE 1: Dynamic friction forces under minimum depth of cut.

response presents a stability limit. Thus, the objective of this work is to characterize the friction acting on the flank of the tool.

In order to identify the friction force of the flank of the tool, the experiments must consider cutting conditions at which the friction on the flank is the dominant excitation. In order to achieve this condition, it is assumed that regenerative effect can be avoided. This can be done considering a low depth of cut and a low feed rate and supposing that the system is properly rigid in order to diminish other external effects. Machining with these conditions, the only force acting will be the friction force on the flank.

The proposed experiment does not pretend to assume that friction is the only force on the cutting process. In addition, it is not trying to argue that the forces on the normal and tangential direction are not coupled in a cutting process. Even more, it is not trying to affirm that neither the regenerative effect nor the process damping exists at all. But, it is worth mentioning that the present work analyzes an especial cutting condition, where the friction force on the tangential direction is isolated and is the dominant effect; therefore it can be analyzed as a single degree of freedom case.

\section{Mathematical Model}

The proposed model is based on the concept of the generalized friction effect [19], which adds two more friction effects to the Coulomb friction, one related to the relative displacement and another related to the relative velocity.

Since in this especial condition the feed is too small, the thrust force ( $x$ direction) has a minimum magnitude, and then the Coulomb friction on the tangential direction can be neglected. Therefore, only two friction effects remain on the tangential direction: one related to the displacement and the other related to the velocity. Therefore, the proposed model is represented as follows (Figure 1):

$$
m\left(\ddot{x}+2 \xi \omega_{n} \dot{x}+\omega_{n}^{2} x\right)=F_{f}\left(x, \dot{x}, \mu_{1}, \mu_{2}\right),
$$

where $x$ represents the relative displacement, $\xi, \omega_{n}$, and $m$ are the damping factor, the natural system frequency, and the equivalent mass, $F_{f}$ is the friction force, and $\mu_{1}$ and $\mu_{2}$ represent both the friction effects.

Expressing (1) in the Laplace domain:

$$
m X(s)\left(s^{2}+2 \xi \omega_{n} s+\omega_{n}^{2}\right)=F_{f}\left(s, \mu_{1}, \mu_{2}\right) .
$$

Solving the equation, the transfer function is obtained as

$$
G(s)=\frac{X(s)}{F_{f}\left(s, \mu_{1}, \mu_{2}\right)}=\frac{1 / m}{s^{2}+2 \xi \omega_{n} s+\omega_{n}^{2}} .
$$

In the above expression, $X(s)$ is the system response, $F_{f}\left(s, \mu_{1}, \mu_{2}\right)$ is the total friction force, and $s$ is the complex variable. Equation (3) can be expressed as the impedance function:

$$
Z\left(\mu_{2}, \mu_{3}, s\right)=\frac{F_{f}\left(s, \mu_{1}, \mu_{2}\right)}{X(s)} .
$$

This function can be obtained experimentally by measuring the force and the displacement at the cutting tool. Considering $s=i \omega$, where $\omega$ is the excitation frequency of the system, the experimental impedance function can be expressed as

$$
Z_{e}(i \omega)=\frac{F_{e}(i \omega)}{X_{e}(i \omega)}
$$

It is assumed that (4) and (5) are equal. Thus, the experimental impedance function can be related to the friction functions $\mu_{1}$ and $\mu_{2}$ if

$$
Z_{e}(i \omega)=Z\left(\mu_{1}, \mu_{2}, i \omega\right) .
$$

Since the friction functions depend only on position and velocity, it is assumed that the friction force has the following form:

$$
F_{f}\left(i \omega, \mu_{1}, \mu_{2}\right)=\mu_{1} X(i \omega)+i \mu_{2} \omega X(i \omega) .
$$

And, in this way, the impedance function becomes

$$
Z_{e}\left(\mu_{1}, \mu_{2}, i \omega\right)=\mu_{1}+i \mu_{2} \omega .
$$

From a preliminary test, it was observed that the friction also varies with respect to the frequency; therefore, the impedance function can be represented as

$$
Z_{e}(i \omega)=C_{1} e^{r_{1} \omega}+i C_{2} e^{r_{2} \omega},
$$

where $C_{1}, C_{2}, r_{1}$, and $r_{2}$ are unknown. This function is similar to the model proposed by Oden and Martins [19].

Therefore, the friction parameters are represented as

$$
\begin{aligned}
& \mu_{1}(\omega)=C_{1} e^{r_{1} \omega} \\
& \mu_{2}(\omega)=\frac{C_{2} e^{r_{2} \omega}}{\omega} .
\end{aligned}
$$

These functions cannot accept negative values; therefore, (10) is transformed into

$$
\begin{aligned}
& \mu_{1}\left(\omega_{0}, \omega\right)=\left(A_{1} e^{B_{1} \omega_{0}}\right) e^{\left(E_{1} \omega_{0}+F_{1}\right) \omega}, \\
& \mu_{2}\left(\omega_{0}, \omega\right)=\frac{\min \left(E_{1} \omega_{0}+F_{1}\right) \geq 0}{\omega}, \\
& \min \left(E_{2} \omega_{0}+F_{2}\right) \geq 0,
\end{aligned}
$$




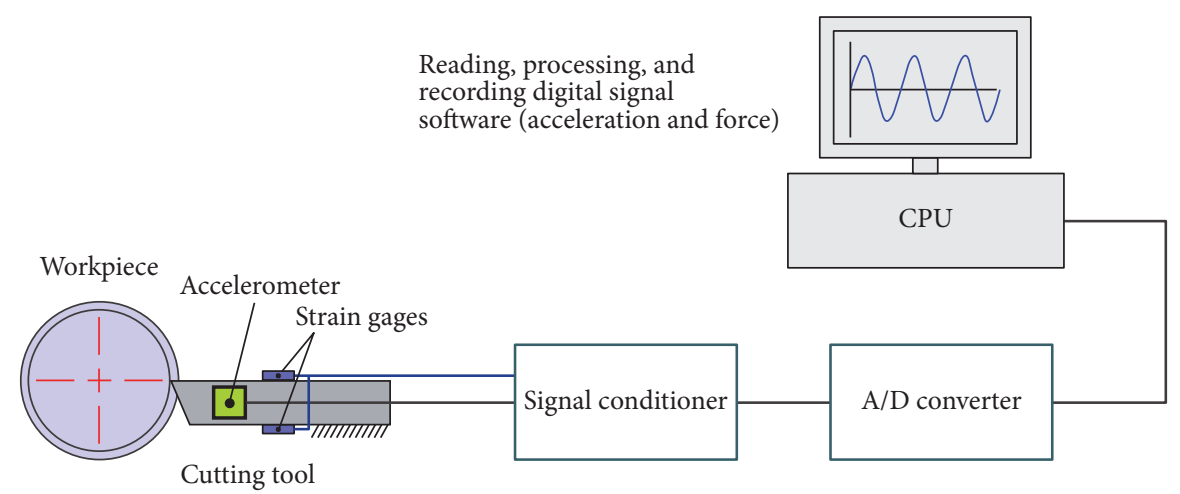

Figure 2: Measurement system.

where $A, B, E$, and $F$ are constants and $\omega_{0}$ and $\omega$ are, respectively, the operation frequency (the rotation speed of the lathe) and the excitation one (tool's vibration frequency). These parameters can be determined measuring the cutting force and the displacement amplitude of the cutting tool under different operation frequencies. This is equivalent to taking measurements under different lathe's spindle speeds.

To take the experimental measurements, the force and the acceleration on the cutting tool where evaluated on an instrumented numeric control lathe.

\section{Experimental Arrangement}

In order to have a continuous cutting process and to minimize the dynamic effects, the tests were conducted on an instrumented CNC lathe. The cutting force was reduced by maintaining low cutting depths, a very rigid support for the work piece, and a minimum lateral feed and working over a previously machined surface to maintain similar initial conditions.

Test specimens were 6026 T- 6 aluminum round rods of $50 \mathrm{~mm}$ diameter. The cutting tools were multilayer coated carbide inserts ( $\mathrm{TiN}, \mathrm{TiCN}$, and $\mathrm{TiC}$ ). The experimental arrangement is shown in Figure 2.

To measure the acceleration a piezo electric accelerometer Kistler K8776A50 and a National Instruments NI 9234 module for signal conditioning were used. The accelerometer was oriented in tangential direction.

The force was measured with two Vishay CEA-060620UW-120 strain gages with a National Instruments NI 9237 module for signal conditioning.

The signals were recorded with a NI CDAQ 9174 data acquisition module at $25.6 \mathrm{kHz}$.

The cutting speed was programmed to have a constant feed rate of $0.05 \mathrm{~mm} / \mathrm{rev}$ and the data were recorded during $10 \mathrm{~s}$. To find the parameters of (9), the next experimental design was conducted.

\section{Experimental Design}

The experimental design consisted of two cutting tool wear levels, four depth of cut levels, and three cutting speed levels (Table 1). The depth of cut and the cutting speed were the
TABLE 1: Test plan of the experimental design, to obtain acceleration $(\mathrm{g})$ and force $(\mathrm{N})$.

\begin{tabular}{lcc}
\hline Test number & Depth of cut $(\mathrm{mm})$ & Cutting speed $(\mathrm{m} / \mathrm{min})$ \\
\hline 1 & 0 & 60 \\
2 & 0 & 150 \\
3 & 0 & 300 \\
4 & 0.05 & 60 \\
5 & 0.05 & 150 \\
6 & 0.05 & 300 \\
7 & 0.1 & 60 \\
8 & 0.1 & 150 \\
9 & 0.1 & 300 \\
10 & 0.2 & 60 \\
11 & 0.2 & 150 \\
12 & 0.2 & 300 \\
\hline
\end{tabular}

control variables. In order to isolate the friction effect on the tangential force, the feed rate was kept as low as possible.

The minimum and maximum cutting speeds were selected according to the tool manufacturer. The acceleration and force data were transformed into the frequency domain using the FFT, and experimental results are shown in the next section.

\section{Experimental Results}

According to the experimental design shown in Table 1, for each test a set of data of the acceleration and force from every experiment was obtained. As an example, Figure 3 shows the acceleration and force original data corresponding to test number 11. Figure 4 shows the frequency spectrum of both signals.

For this particular case, it can be noticed that the accelerometer and the strain gages show high amplitude picks within the same frequency range $(4000$ to $4250 \mathrm{~Hz})$. This frequency corresponds to the signal produced by the friction force. Therefore, there is a correlation between the two signals, and it means that the friction force is creating a particular response on the tool at these frequencies. 


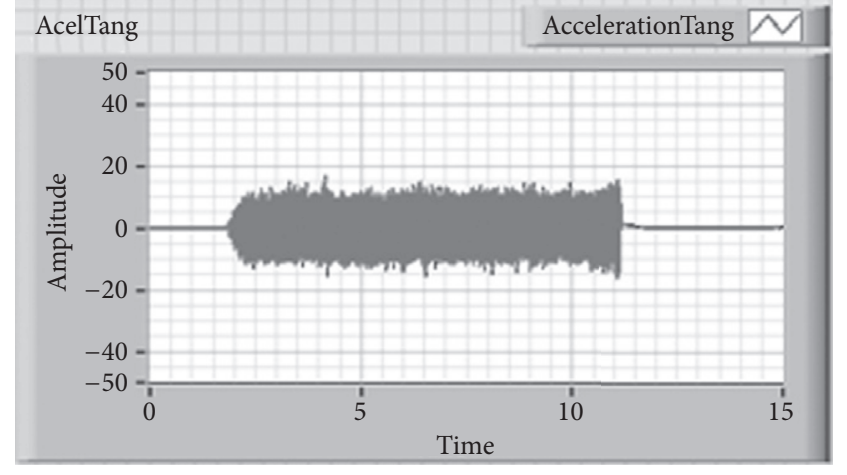

(a)

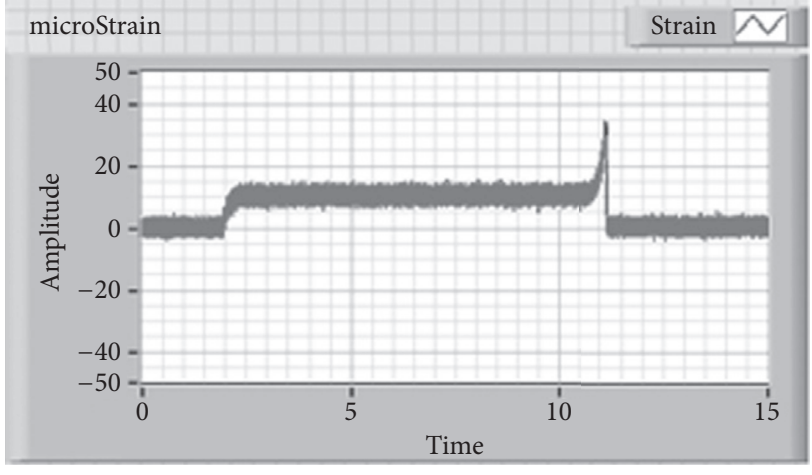

(b)

Figure 3: Acceleration and strain data of test 11.

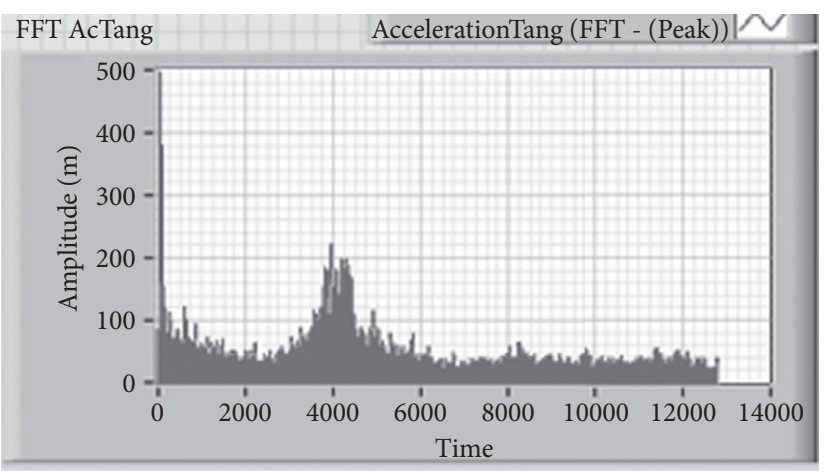

(a)

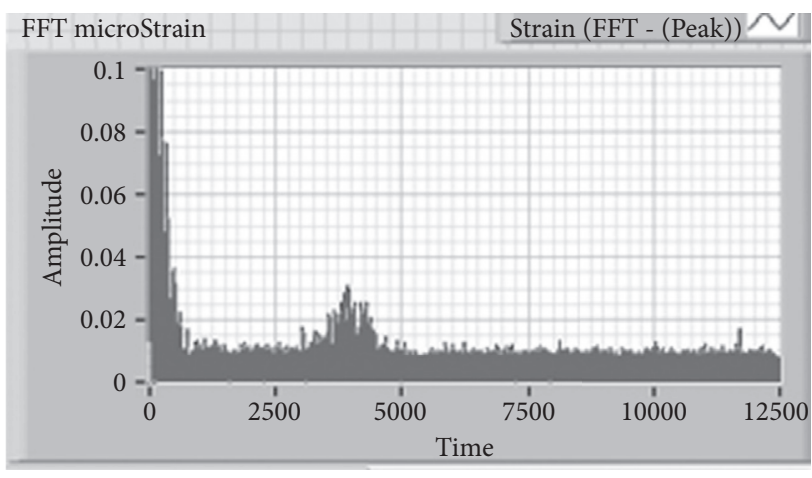

(b)

FIGURE 4: Frequency domain of the acceleration and strain data of test 11.

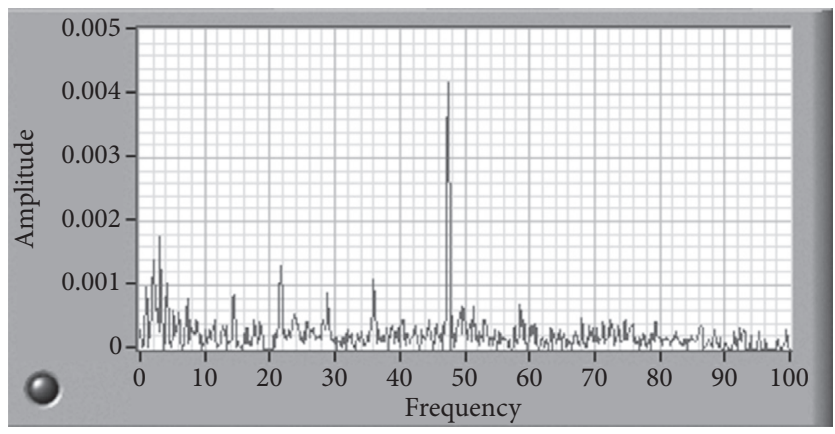

FIGURE 5: Filtered FFT signal of the acceleration (g), corresponding to $0 \mathrm{~mm}$ and $60 \mathrm{~m} / \mathrm{min}$.

5.1. Data Processing. In order to identify only the signals associated with the contact between the tool and the work piece, the signals were filtered subtracting the noncontact state (where there was no cutting force). The transfer and impedance functions were also cleaned up to eliminate the transient effects, low frequency noise, and electric noise frequencies.

As an example, the frequency spectrums, after filtering the data, of the acceleration and force data obtained at test 1 are shown in Figures 5 and 6.

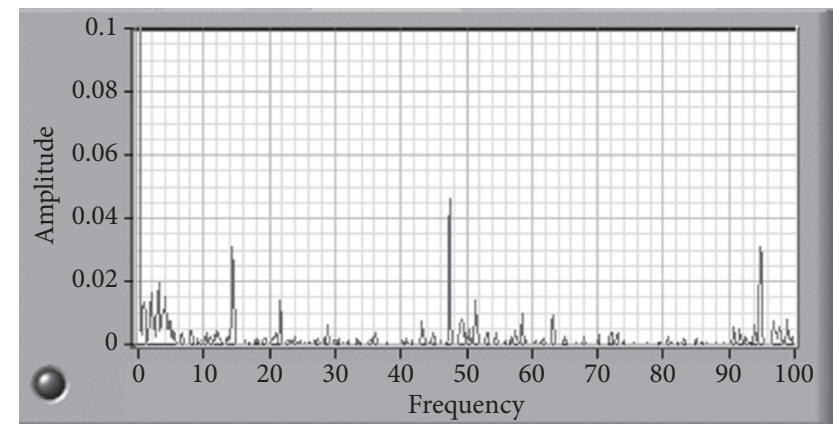

FIGURE 6: Filtered FFT signal of the force $(\mathrm{kg})$, corresponding to $0 \mathrm{~mm}$ and $60 \mathrm{~m} / \mathrm{min}$.

The response displacement $X(j \omega)$ is obtained from the acceleration signal $A(j \omega)$, according to the following relation:

$$
X(j \omega)=-\frac{A(j \omega)}{\omega^{2}}
$$

5.2. Determining the Friction Function. In order to obtain the friction force functions, a curve fitting of the real and imaginary parts of the impedance function was carried out. 
TABLE 2: Parameter values in relation to the operation speed, obtained with worn insert.

\begin{tabular}{|c|c|c|c|c|c|}
\hline \multirow{2}{*}{$\begin{array}{l}\text { Cut } \\
\mathrm{m} / \mathrm{min}\end{array}$} & \multirow{2}{*}{$\begin{array}{c}\text { Operation } \\
\mathrm{Hz}\left(\omega_{0}\right)\end{array}$} & \multicolumn{2}{|c|}{ Real part } & \multicolumn{2}{|c|}{ Imaginary part } \\
\hline & & $C 1$ & $r 1$ & $C 2$ & $r 2$ \\
\hline \multicolumn{6}{|c|}{ Depth of cut zero } \\
\hline 60 & 7.21 & 18876 & 0.0693 & 15270 & 0.0599 \\
\hline 150 & 17.53 & 25076 & 0.0295 & 5898.9 & 0.0366 \\
\hline 300 & 34.66 & 73249 & 0.0141 & 5263.3 & 0.0365 \\
\hline \multicolumn{6}{|c|}{ Depth of cut $0.05 \mathrm{~mm}$} \\
\hline 60 & 7.30 & 3581.9 & 0.1307 & 538.22 & 0.1454 \\
\hline 150 & 17.88 & 508.22 & 0.0572 & 230.39 & 0.051 \\
\hline 300 & 36.19 & 1974.3 & 0.0413 & 712.24 & 0.0333 \\
\hline \multicolumn{6}{|c|}{ Depth of cut $0.1 \mathrm{~mm}$} \\
\hline 60 & 7.58 & 1955.1 & 0.0369 & 712.57 & 0.0695 \\
\hline 150 & 18.75 & 700.72 & 0.034 & 156.57 & 0.0867 \\
\hline 300 & 38.18 & 2545.3 & 0.0379 & 188.7 & 0.0567 \\
\hline \multicolumn{6}{|c|}{ Depth of cut $0.2 \mathrm{~mm}$} \\
\hline 60 & 8.24 & 698.46 & 0.0976 & 1428.5 & 0.0578 \\
\hline 150 & 20.00 & 84.04 & 0.0471 & 1443.8 & 0.0002 \\
\hline 300 & 35.75 & 2086.4 & 0.0382 & 1288.4 & 0.0292 \\
\hline
\end{tabular}

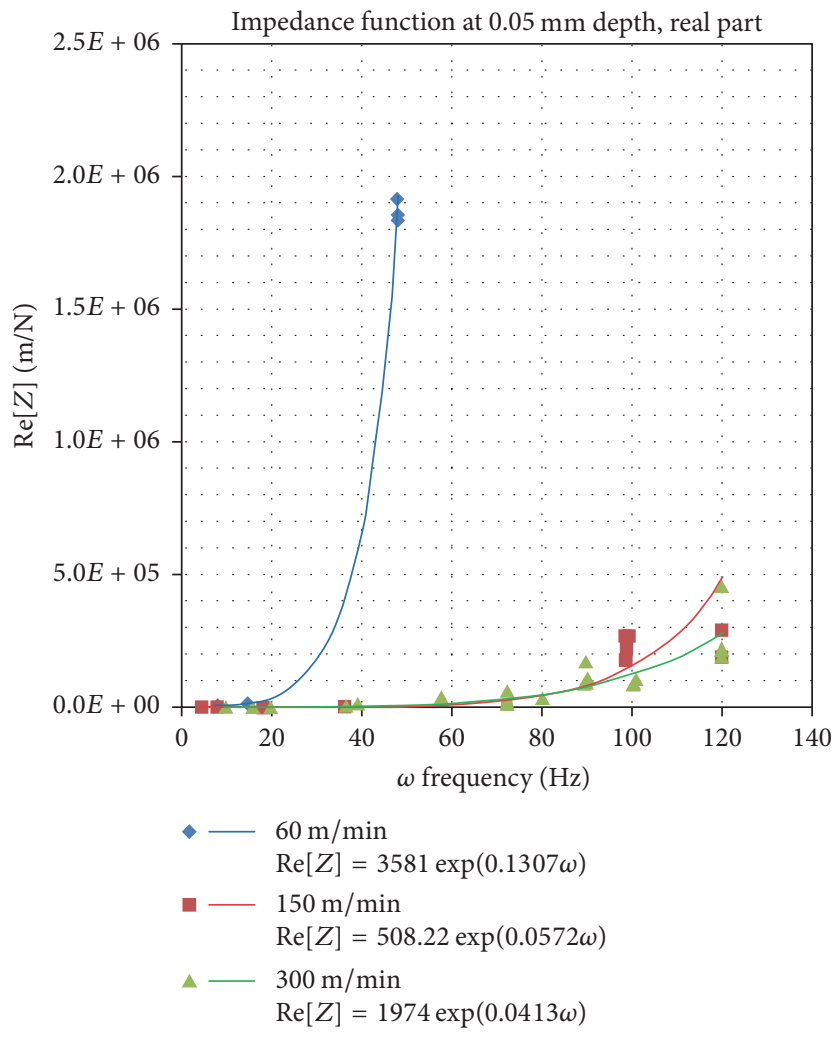

FIGURE 7: Real part of the impedance function, at $0.05 \mathrm{~mm}$ depth of cut, under 60,150 , and $300 \mathrm{~m} / \mathrm{min}$ of cutting speed.

The force and acceleration data were recorded according to the test plan (Table 1). Figures 7 and 8 show results of the impedance function for tests 4,5 , and 6 , and they also show the curve fitting functions. In this way, the parameters of the

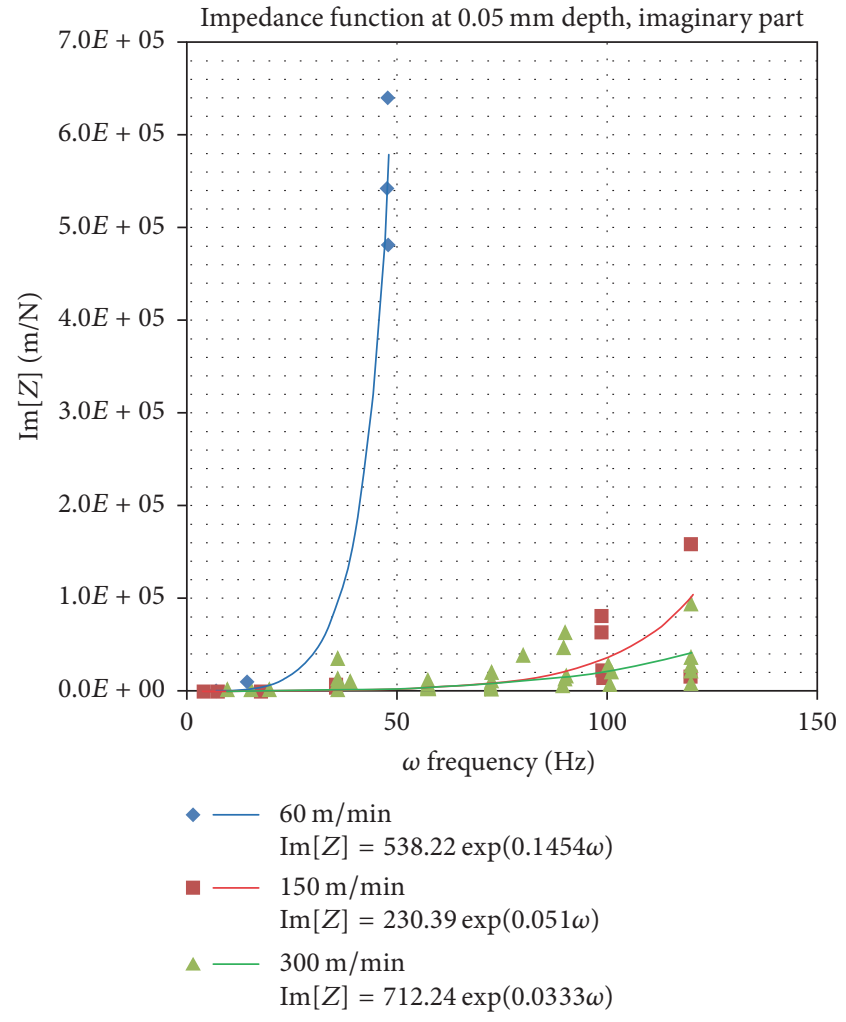

FIGURE 8: Imaginary part of the impedance function, at $0.05 \mathrm{~mm}$ depth of cut, under 60,150 , and $300 \mathrm{~m} / \mathrm{min}$ of cutting speed.

proposed curves of (9) were obtained (Tables 2 and 3). The constants $A_{i}, B_{i}, E_{i}$, and $F_{i}$ of the parameters were obtained using (11). The values of these constants are shown in Tables 4 and 5. 
TABLE 3: Parameter values in relation to the operation speed, obtained with new insert.

\begin{tabular}{|c|c|c|c|c|c|}
\hline \multirow{2}{*}{$\begin{array}{l}\text { Cut } \\
\mathrm{m} / \mathrm{min}\end{array}$} & \multirow{2}{*}{$\begin{array}{c}\text { Operation } \\
\mathrm{Hz}\left(\omega_{0}\right)\end{array}$} & \multicolumn{2}{|c|}{ Real part } & \multicolumn{2}{|c|}{ Imaginary part } \\
\hline & & $C 1$ & $r 1$ & $C 2$ & $r 2$ \\
\hline \multicolumn{6}{|c|}{ Depth of cut zero } \\
\hline 60 & 8.13 & 12238 & 0.0632 & 5269.5 & 0.0657 \\
\hline 150 & 18.84 & 2165.5 & 0.0562 & 950.46 & 0.055 \\
\hline 300 & 36.33 & 4262.1 & 0.039 & 505.47 & 0.044 \\
\hline \multicolumn{6}{|c|}{ Depth of cut $0.05 \mathrm{~mm}$} \\
\hline 60 & 8.38 & 16387 & 0.0687 & 13526 & 0.0522 \\
\hline 150 & 19.15 & 1090.6 & 0.0272 & 180.63 & 0.0278 \\
\hline 300 & 37.63 & 1781.3 & 0.0358 & 92.231 & 0.0521 \\
\hline \multicolumn{6}{|c|}{ Depth of cut $0.1 \mathrm{~mm}$} \\
\hline 60 & 9.13 & 120.31 & 0.1176 & 583.79 & 0.0778 \\
\hline 150 & 20.25 & 768.48 & 0.0302 & 510.21 & 0.0262 \\
\hline 300 & 38.68 & 7417.9 & 0.0242 & 925.47 & 0.0376 \\
\hline \multicolumn{6}{|c|}{ Depth of cut $0.2 \mathrm{~mm}$} \\
\hline 60 & 8.93 & 69.766 & 0.1434 & 498.3 & 0.0609 \\
\hline 150 & 23.47 & 654.78 & 0.0341 & 193.18 & 0.0344 \\
\hline 300 & 40.32 & 6562.8 & 0.0313 & 982.19 & 0.0448 \\
\hline
\end{tabular}

TABLE 4: Values of the parameter's constants of the friction coefficient functions, in the case of the worn insert.

\begin{tabular}{ccccccccccc}
\hline \multicolumn{2}{c}{ Worn insert } & \multicolumn{2}{c}{ Depth of cut zero } & \multicolumn{2}{c}{ Depth of cut $0.05 \mathrm{~mm}$} & \multicolumn{2}{c}{ Depth of cut $0.1 \mathrm{~mm}$} & \multicolumn{2}{c}{ Depth of cut $0.2 \mathrm{~mm}$} \\
\multicolumn{2}{c}{ Parameter } & Parameter & $\mu_{1}$ & $\mu_{2}$ & $\mu_{1}$ & $\mu_{2}$ & $\mu_{1}$ & $\mu_{2}$ & $\mu_{1}$ & $\mu_{2}$ \\
\hline \multirow{2}{*}{$C_{i}$} & $A_{i}$ & 11946 & 15760 & 1885.2 & 324.76 & 1096.8 & 618.64 & 175.42 & 1506.6 \\
& $B_{i}$ & 0.0507 & -0.036 & -0.01 & 0.0154 & 0.0151 & -0.038 & 0.0488 & -0.004 \\
$r_{i}$ & $E_{i}$ & -0.0019 & -0.0008 & -0.0028 & -0.0036 & $5.00 E-05$ & -0.0005 & -0.0021 & -0.0009 \\
& $F_{i}$ & 0.0752 & 0.0595 & 0.1347 & 0.1493 & 0.0352 & 0.0827 & 0.1052 & 0.0479 \\
\hline
\end{tabular}

TABLE 5: Values of the parameter's constants of the friction coefficient functions, in the case of the new insert.

\begin{tabular}{cccccccccc}
\hline & \multicolumn{2}{c}{ New insert } & \multicolumn{2}{c}{ Depth of cut zero } & \multicolumn{2}{c}{ Depth of cut $0.05 \mathrm{~mm}$} & \multicolumn{2}{c}{ Depth of cut $0.1 \mathrm{~mm}$} & \multicolumn{2}{c}{ Depth of cut $0.2 \mathrm{~mm}$} \\
Parameter & Parameter & $\mu_{1}$ & $\mu_{2}$ & $\mu_{1}$ & $\mu_{2}$ & $\mu_{1}$ & $\mu_{2}$ & $\mu_{1}$ & $\mu_{2}$ \\
\hline \multirow{2}{*}{$C_{i}$} & $A_{i}$ & 9099.1 & 7146.9 & 12930 & 17994 & 38.695 & 439.81 & 20.13 & 257.14 \\
& $B_{i}$ & -0.03 & -0.079 & -0.065 & -0.156 & 0.1378 & 0.0173 & 0.1446 & 0.0236 \\
$r_{i}$ & $E_{i}$ & -0.0009 & -0.0008 & -0.001 & 0.0001 & -0.0029 & -0.0012 & -0.0035 & -0.0005 \\
& $F_{i}$ & 0.0712 & 0.0708 & 0.0646 & 0.041 & 0.1226 & 0.0735 & 0.154 & 0.0584 \\
\hline
\end{tabular}

Finally, the friction functions in terms of the operation and excitation frequencies are found. Therefore, the equations for each cutting condition are summarized as follows.

\subsubsection{New Insert}

\section{Depth of Cut Zero}

$$
\begin{aligned}
& \mu_{1,0}\left(\omega, \omega_{i}\right)=\left(9099.1 e^{-0.03 \omega}\right) e^{(-0.0009 \omega+0.0712) \omega_{i}} \\
& \mu_{2,0}\left(\omega, \omega_{i}\right)=\frac{\left(7146.9 e^{-0.079 \omega}\right) e^{(-0.0008 \omega+0.0708) \omega_{i}}}{\omega_{i}} .
\end{aligned}
$$

Depth of Cut $0.05 \mathrm{~mm}$

$$
\begin{aligned}
& \mu_{1,0.05}\left(\omega, \omega_{i}\right)=\left(12930 e^{-0.065 \omega}\right) e^{(-0.001 \omega+0.0646) \omega_{i}} \\
& \mu_{2,0.05}\left(\omega, \omega_{i}\right)=\frac{\left(17994 e^{-0.156 \omega}\right) e^{(0.0001 \omega+0.041) \omega_{i}}}{\omega_{i}} .
\end{aligned}
$$

Depth of Cut $0.1 \mathrm{~mm}$

$$
\begin{aligned}
& \mu_{1,0.1}\left(\omega, \omega_{i}\right)=\left(38.695 e^{0.1378 \omega}\right) e^{(-0.0029 \omega+0.1226) \omega_{i}} \\
& \mu_{2,0.1}\left(\omega, \omega_{i}\right)=\frac{\left(439.81 e^{0.0173 \omega}\right) e^{(-0.0012 \omega+0.0735) \omega_{i}}}{\omega_{i}} .
\end{aligned}
$$


TABLE 6: Values of the parameter's constants of the friction coefficient functions, in the case of the new insert.

\begin{tabular}{|c|c|c|c|c|c|c|c|c|}
\hline \multirow{3}{*}{ Depth of cut } & \multicolumn{8}{|c|}{ New } \\
\hline & \multicolumn{4}{|c|}{$\mu_{1}$} & \multicolumn{4}{|c|}{$\mu_{2}$} \\
\hline & $A_{i}$ & $B_{i}$ & $E_{i}$ & $F_{i}$ & $A_{i}$ & $B_{i}$ & $E_{i}$ & $F_{i}$ \\
\hline 0 & 9099 & -0.03 & -0.0009 & 0.0721 & 7146 & -0.079 & -0.0008 & 0.0708 \\
\hline 0.05 & 12930 & -0.065 & -0.001 & 0.0646 & 17994 & -0.156 & 0.0001 & 0.041 \\
\hline 0.1 & 38.695 & 0.1378 & -0.0029 & 0.1226 & 439.81 & 0.0173 & -0.0012 & 0.0735 \\
\hline 0.2 & 20.13 & 0.1446 & -0.0035 & 0.154 & 257.14 & 0.0236 & -0.0005 & 0.0584 \\
\hline
\end{tabular}

TABLE 7: Values of the parameter's constants of the friction coefficient functions, in the case of the new insert.

\begin{tabular}{|c|c|c|c|c|c|c|c|c|}
\hline \multirow{3}{*}{ Depth of cut } & \multicolumn{8}{|c|}{ Worn } \\
\hline & \multicolumn{4}{|c|}{$\mu_{1}$} & \multicolumn{4}{|c|}{$\mu_{2}$} \\
\hline & $A_{i}$ & $B_{i}$ & $E_{i}$ & $F_{i}$ & $A_{i}$ & $B_{i}$ & $E_{i}$ & $F_{i}$ \\
\hline 0 & 1194 & 0.0507 & -0.0019 & 0.0752 & 15760 & -0.036 & -0.0008 & 0.0595 \\
\hline 0.05 & 1885.2 & -0.01 & -0.0028 & 0.1347 & 324.76 & 0.0154 & -0.003 & 0.1493 \\
\hline 0.1 & 1096.8 & 0.0151 & 0.00005 & 0.0352 & 618.64 & -0.038 & -0.0005 & 0.0827 \\
\hline 0.2 & 175.42 & 0.0488 & -0.0021 & 0.052 & 1506.6 & -0.004 & -0.0009 & 0.0479 \\
\hline
\end{tabular}

Depth of Cut $0.2 \mathrm{~mm}$

$$
\begin{aligned}
& \mu_{1,0.2}\left(\omega, \omega_{i}\right)=\left(20.13 e^{0.1446 \omega}\right) e^{(-0.0035 \omega+0.154) \omega_{i}} \\
& \mu_{2,0.2}\left(\omega, \omega_{i}\right)=\frac{\left(257.14 e^{0.0236 \omega}\right) e^{(-0.0005 \omega+0.0584) \omega_{i}}}{\omega_{i}} .
\end{aligned}
$$

\subsubsection{Worn Insert}

Depth of Cut Zero

$$
\begin{aligned}
& \mu_{1,0}\left(\omega, \omega_{i}\right)=\left(11946 e^{0.0507 \omega}\right) e^{(-0.0019 \omega+0.0752) \omega_{i}} \\
& \mu_{2,0}\left(\omega, \omega_{i}\right)=\frac{\left(15760 e^{-0.036 \omega}\right) e^{(-0.0008 \omega+0.0595) \omega_{i}}}{\omega_{i}} .
\end{aligned}
$$

\section{Depth of Cut $0.05 \mathrm{~mm}$}

$$
\begin{aligned}
& \mu_{1,0.05}\left(\omega, \omega_{i}\right)=\left(1885.2 e^{-0.01 \omega}\right) e^{(-0.0028 \omega+0.1347) \omega_{i}} \\
& \mu_{2,0.05}\left(\omega, \omega_{i}\right)=\frac{\left(324.76 e^{0.0154 \omega}\right) e^{(-0.0036 \omega+0.1493) \omega_{i}}}{\omega_{i}} .
\end{aligned}
$$

Depth of Cut $0.1 \mathrm{~mm}$

$$
\begin{aligned}
& \mu_{1,0.1}\left(\omega, \omega_{i}\right)=\left(1096.8 e^{0.0151 \omega}\right) e^{(0.00005 \omega+0.0352) \omega_{i}} \\
& \mu_{2,0.1}\left(\omega, \omega_{i}\right)=\frac{\left(618.64 e^{-0.038 \omega}\right) e^{(-0.0005 \omega+0.0827) \omega_{i}}}{\omega_{i}} .
\end{aligned}
$$

\section{Depth of Cut $0.2 \mathrm{~mm}$}

$$
\begin{aligned}
& \mu_{1,0.2}\left(\omega, \omega_{i}\right)=\left(175.42 e^{0.0488 \omega}\right) e^{(-0.0021 \omega+0.1052) \omega_{i}} \\
& \mu_{2,0.2}\left(\omega, \omega_{i}\right)=\frac{\left(1506.6 e^{-0.004 \omega}\right) e^{(-0.0009 \omega+0.0479) \omega_{i}}}{\omega_{i}} .
\end{aligned}
$$

The constant values for these equations are listed in Tables 6 and 7.

Results for $0.05 \mathrm{~mm}$ depth of cut, for a worn and new insert, are shown in Figures 9 and 10.

By keeping only the friction force on the flank as excitation force, it is possible to identify the friction function. The data was processed using the impedance function.

\section{Discussion}

From Figures 7 and 8 it is clear that friction depends on the cutting speed, and the exponential form corresponds to a time delay phenomenon. In all cases the real part and the imaginary part show an exponential form, which corresponds to the slip-stick friction theory [19]. Another important aspect that can be seen in these figures is that the friction force is higher at low cutting speeds. This condition is also a good indication that friction decreases with an increment in speed.

The effect of the depth of cut can be identified in Tables 6 and 7. $\mu_{1}$ is the friction function related to the relative displacement; in the case of a new insert, the $A_{i}$ coefficient changes several orders of magnitude at high depths of cut (0.1 and 0.2), whereas for the worn insert the changes are less significant. A similar pattern is found for the $\mu_{2}$, which is related to the relative velocity.

Analyzing the form of the friction functions, $A_{i}$ and $B_{i}$ represent the amplitude of the friction force, and $E_{i}$ and $F_{i}$ represent the time delay parameters in the sense of the slip and stick concept.

Figures 9 and 10 show the calculated values of $\mu_{1}$ and $\mu_{2}$ for different cutting speeds. They show a good correlation with the experimental data (Figures 7 and 8 ) and they show a reduction on the friction forces at higher speeds. 


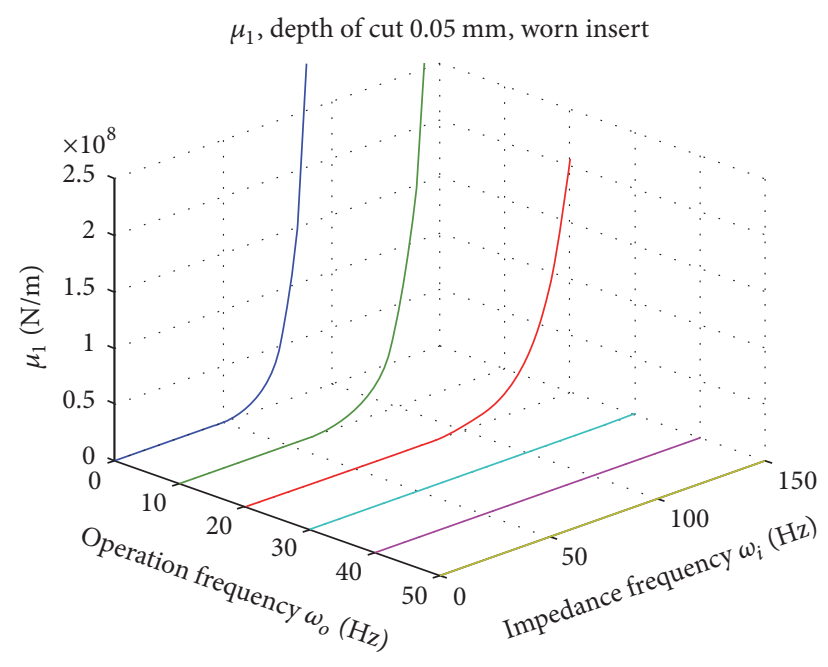

$\mu_{1}$, depth of cut $0.05 \mathrm{~mm}$, new insert

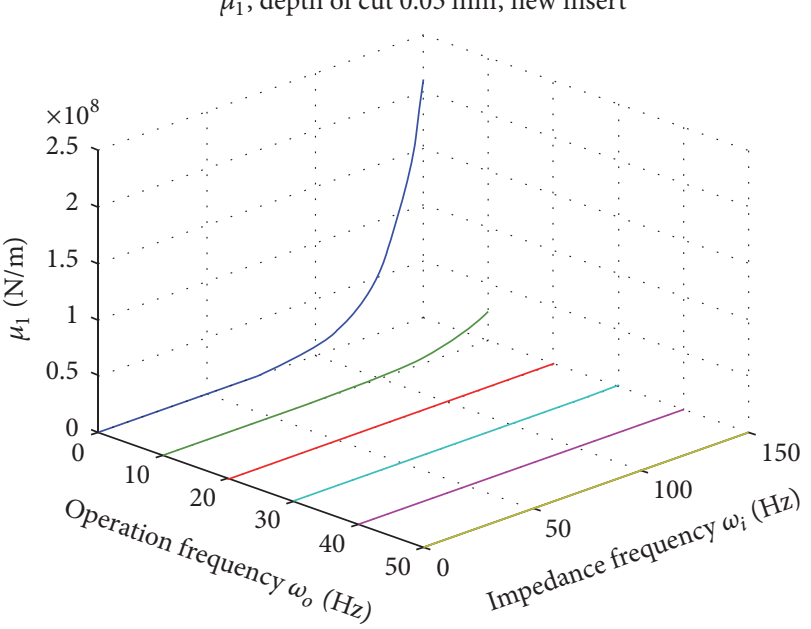

FIGURE 9: Comparison of $\mu 1$, at $0.05 \mathrm{~mm}$ of depth of cut, worn versus new insert.

\section{Conclusions}

From the analysis of the experimental data, it was found that the friction force on the flank of a tool has a complex function. It depends not only on the relative displacement and velocity between the tool and the working piece, but also on the cutting speed, the depth of cut, and the dynamic response (excitation frequency). Since the friction force depends on the dynamic response, it can be considered as a source of instability during a cutting process.

The response in the frequency domain corresponds to a phenomenon described by a time delay function. Both functions, associated with the displacement and the velocity, have similar patterns showing a time delay behavior. This delay is equivalent to the stick-slip principle, but the difference from a general friction theory is that the friction on the flank is highly influenced by the process conditions, and this dependency is nonlinear.

The nonlinear relation between the friction force and the cutting parameters was obtained using the impedance function in the frequency domain. The impedance function

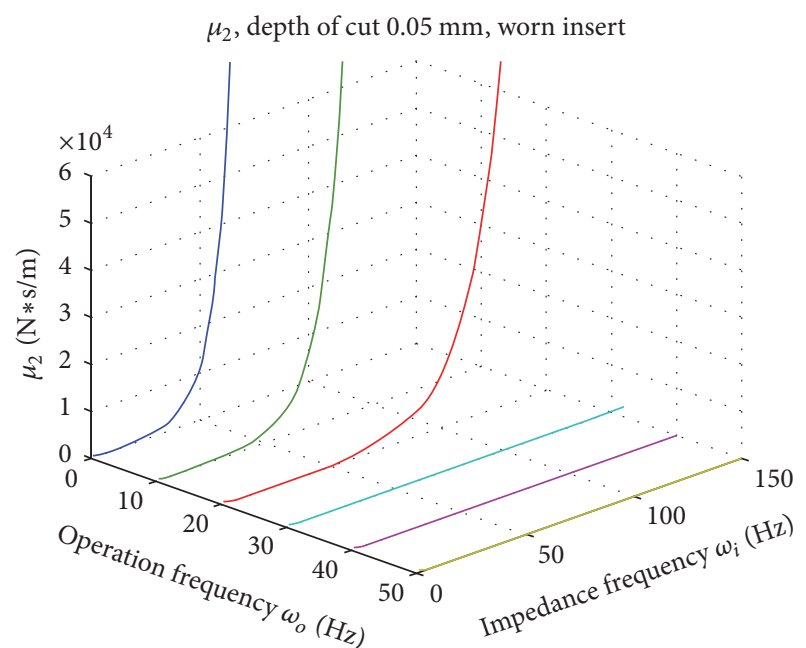

$\mu_{2}$, depth of cut $0.05 \mathrm{~mm}$, new insert

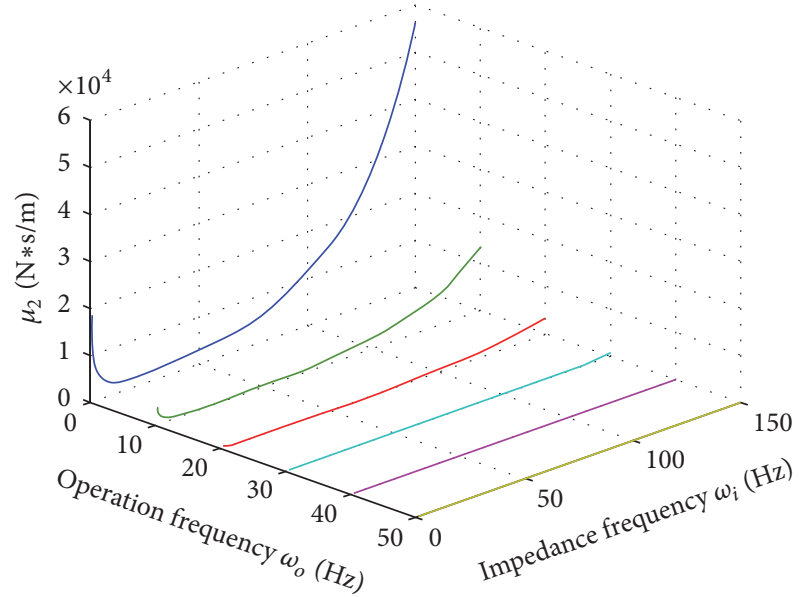

Figure 10: Comparison of $\mu 2$, at $0.05 \mathrm{~mm}$ of depth of cut, worn versus new insert.

is able to identify the characteristic behavior of the friction phenomenon, isolating the other dynamic effects. In this work, it was possible to identify the characteristic frequency of the friction force at the acceleration data, as well as at the force data; thus, the impedance was reliably calculated. This procedure can be applied to other cutting processes such a milling or drilling where the friction on the flank is higher.

Finally, we found that the friction force on the flank of the tool is identified only when the depth of cut is kept as minimum as possible, and the data is processed using the impedance function evaluated at the friction frequencies.

\section{Conflicts of Interest}

The authors declare that there are no conflicts of interest regarding the publication of this paper.

\section{Acknowledgments}

This work was supported by Conacyt Grant no. 220475. 


\section{References}

[1] D. Ulutan and T. Özel, "Determination of tool friction in presence of flank wear and stress distribution based validation using finite element simulations in machining of titanium and nickel based alloys," Journal of Materials Processing Technology, vol. 213, no. 12, pp. 2217-2237, 2013.

[2] P. Oxley, Mechanics of machining, E. Horwood, Chichester, 1989.

[3] A. O. Tay, M. G. Stevenson, and G. d. Davis, "Using the finite element method to determine temperature distributions in orthogonal machining," Proceedings of the Institution of Mechanical Engineers, vol. 1-196, no. 188, pp. 627-638, 1974.

[4] G. R. Johnson y and W. Cook, A Constitutive Model And Data for Metals Subjected to Large Strains, High Strain Rates and High Temperatures, The Hague, Netherlands, 1983.

[5] T. Özel and T. Altan, "Determination of workpiece flow stress and friction at the chip-tool contact for high-speed cutting," International Journal of Machine Tools and Manufacture, vol. 40, no. 1, pp. 133-152, 2000.

[6] T. Özel and E. Zeren, "Determination of work material flow stress and friction for FEA of machining using orthogonal cutting tests," Journal of Materials Processing Technology, vol. 153-154, no. 1-3, pp. 1019-1025, 2004.

[7] C. Nobel, U. Hofmann, F. Klocke, D. Veselovac, and H. Puls, "Application of a new, severe-condition friction test method to understand the machining characteristics of $\mathrm{Cu}-\mathrm{Zn}$ alloys using coated cutting tools," Wear, vol. 344-345, pp. 58-68, 2015.

[8] T. H. C. Childs, "Friction modelling in metal cutting," Wear, vol. 260, no. 3, pp. 310-318, 2006.

[9] T. Childs, M. Dirikolu, M. Sammons, K. Maekawa, and T. Kitagawa, "Experiments on and finite element modelling of turning free-cutting steels at cutting speeds up to $200 \mathrm{~m} / \mathrm{min}$," in Proceedings of the 1st French and German Conference on High Speed Machining, vol. 523-524, pp. 325-331, 1997.

[10] A. Moufki, A. Molinari, and D. Dudzinski, "Modelling of orthogonal cutting with a temperature dependent friction law," Journal of the Mechanics and Physics of Solids, vol. 46, no. 10, pp. 2103-2138, 1998.

[11] T. Özel, "The influence of friction models on finite element simulations of machining," International Journal of Machine Tools and Manufacture, vol. 46, no. 5, pp. 518-530, 2006.

[12] T. H. C. Childs, "Numerical experiments on the influence of material and other variables on plane strain continuous chip formation in metal machining," International Journal of Mechanical Sciences, vol. 48, no. 3, pp. 307-322, 2006.

[13] P. J. Arrazola, D. Ugarte, and X. Domínguez, "A new approach for the friction identification during machining through the use of finite element modeling," International Journal of Machine Tools and Manufacture, vol. 48, no. 2, pp. 173-183, 2008.

[14] S. Atlati, B. Haddag, M. Nouari, and A. Moufki, "Effect of the local friction and contact nature on the Built-Up Edge formation process in machining ductile metals," Tribology International, vol. 90, pp. 217-227, 2015.

[15] M. Wiercigroch and A. M. Krivtsov, "Frictional chatter in orthogonal metal cutting," Philosophical Transactions of the Royal Society A, vol. 359, no. 1781, pp. 713-738, 2001.

[16] M. K. Das and S. A. Tobias, "The relation between the static and the dynamic cutting of metals," International Journal of Machine Tool Design and Research, vol. 7, no. 2, pp. 63-89, 1967.

[17] T. R. Sisson and R. L. Kegg, "An explanation of low-speed chatter effects," ASME Journal of Engineering for Industry, vol. 91, no. 4, pp. 951-958, 1969.
[18] Y. Altintas, M. Eynian, and H. Onozuka, "Identification of dynamic cutting force coefficients and chatter stability with process damping," CIRP Annals: Manufacturing Technology, vol. 57, no. 1, pp. 371-374, 2008.

[19] J. T. Oden and J. A. Martins, "Models and computational methods for dynamic friction phenomena," Computer Methods in Applied Mechanics and Engineering, vol. 52, no. 1-3, pp. 527634, 1985. 


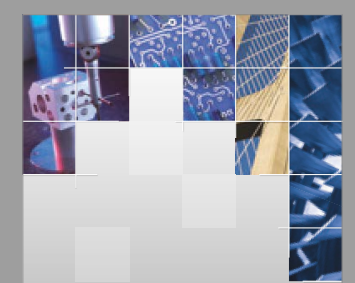

\section{Enfincering}
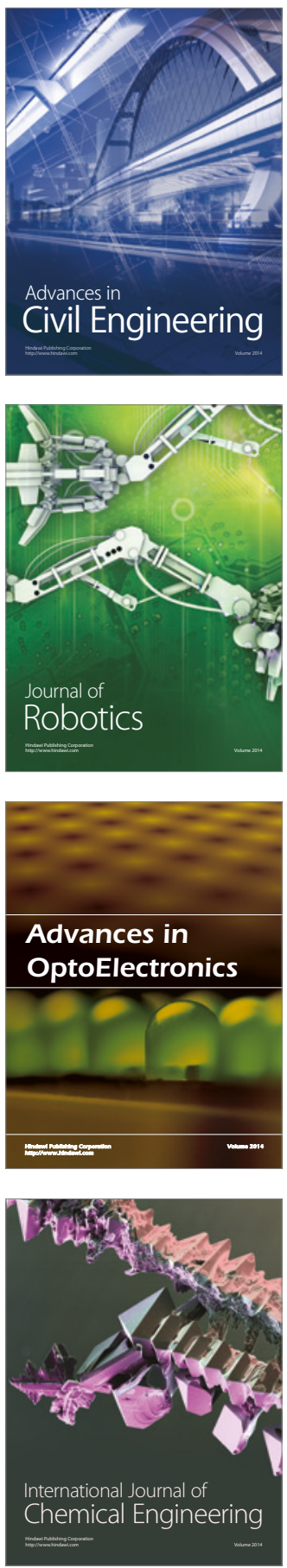

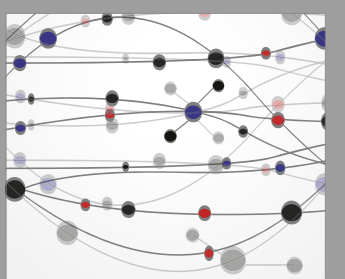

The Scientific World Journal

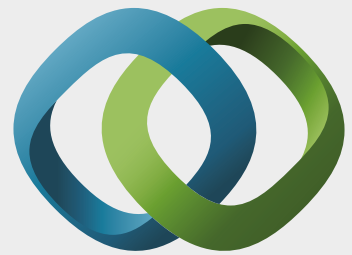

\section{Hindawi}

Submit your manuscripts at

https://www.hindawi.com
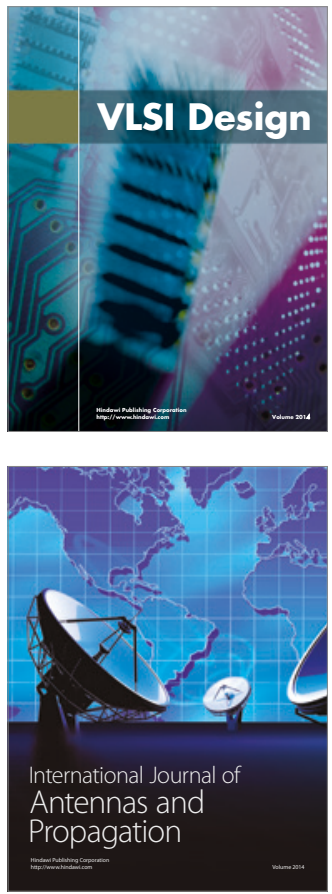

\section{Rotating}

Machinery
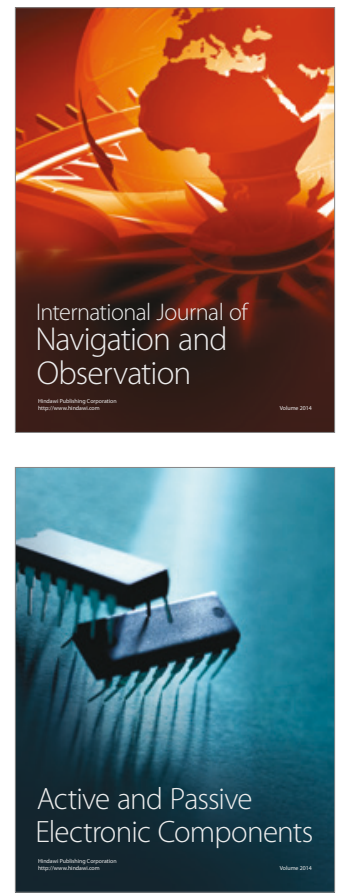
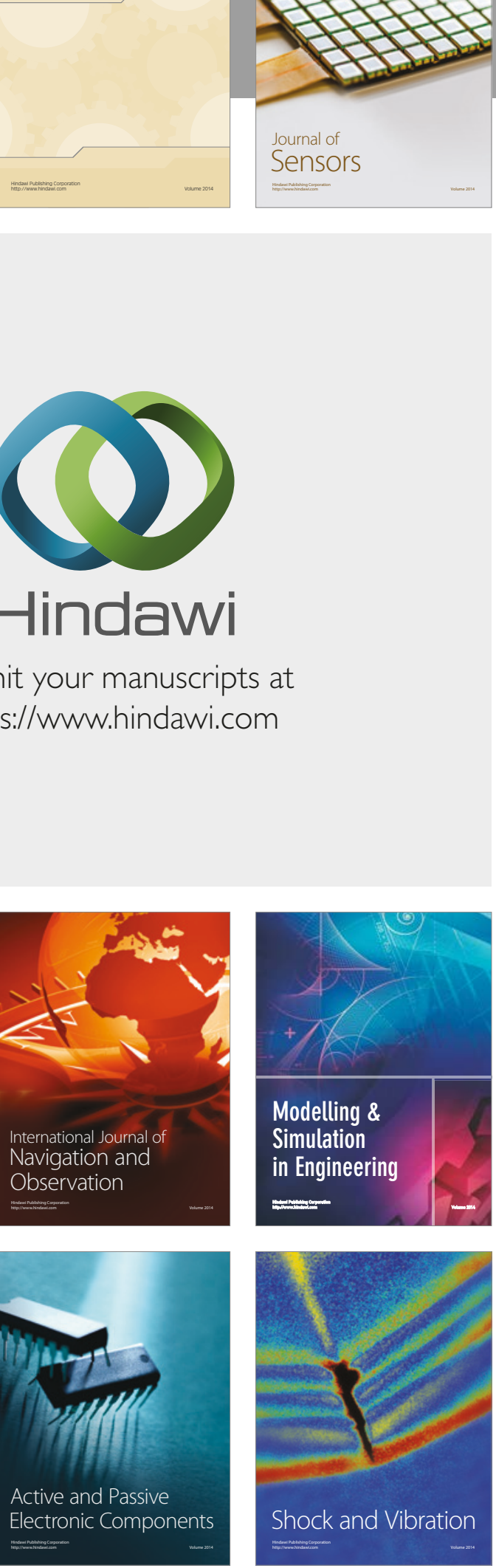
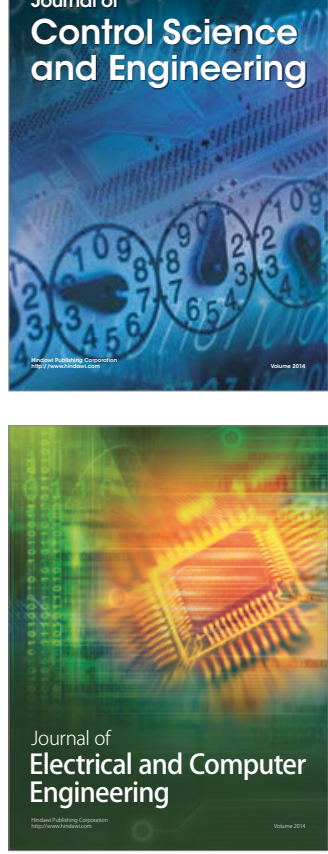

Distributed

Journal of

Control Science

and Engineering
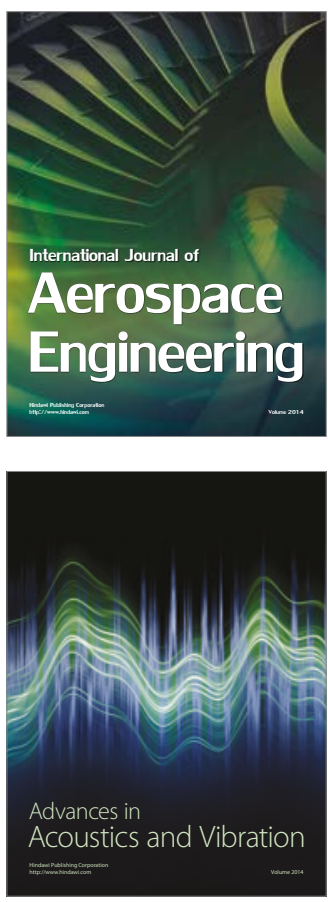

Sensor Networks 